\title{
METODOLOGIAS E ENSINO DE CIÊNCIAS PARA SURDOS
}

\author{
METHODOLOGIES AND SCIENCE TEACHING FOR DEAF PEOPLE
}

\author{
Gabriele Raquel Schneider Pires ${ }^{1}$ \\ Renan Bornholdt ${ }^{2}$
}

RESUMO: É direito de todo cidadão acesso a qualidade de ensino e igualdade de oportunidades, visto que a inclusão é um processo onde você insere um sujeito e o inclui como parte de um todo. Na educação de surdos, o processo de inclusão se dá na inserção do sujeito em classe regular, direito esse que historicamente lhe foi negado, carregando consigo uma série de preconceitos e desentendimentos. Neste contexto, o presente artigo tem como objetivo explicar melhor quem é o sujeito surdo, como ocorreu o processo de ensino através da história, bem como orientar sobre as diferentes metodologias e adaptações norteadoras do ensino de ciências para alunos surdos. Para tal, a metodologia usada foi revisão bibliográfica, foi buscado artigos e teses que esclarecesse o tema central. Ao final, foi concluído que ainda há muito o que buscar na compreensão de uma total inclusão e suporte para os surdos em âmbito escolar, embora as metodologias atuais como o bilinguismo busquem uma melhor prática, ainda há várias lacunas e melhorias que podem ser exploradas.

Palavras-chave: Surdos. Pedagogia. Ensino. Ciências. Inclusão.

ABSTRACT: It is the right of every citizen to access quality education and equal opportunities, since inclusion is a process where you insert a subject and include him as part of a whole. In deaf education, the inclusion process takes place in the inclusion of the subject in a regular class, a right that has historically been denied, carrying with it a series of prejudices and misunderstandings. In this context, the present article aims to better explain who is the deaf person, how the teaching process occurred through history, as well as to guide about the different methodologies and guiding adaptations of science education for deaf students. To this end, the use was a bibliographic review, articles and theses were sought to clarify the central theme. In the end, it was concluded that there is still a lot to look for in understanding full inclusion and support for the deaf in the school environment, although current methodologies such as bilingualism seek better practice, there are still several gaps and improvements that can be explored.

Keywords: Deaf. Pedagogy. Teaching. Inclusion.

\footnotetext{
I Acadêmica em Licenciatura em Ciências Biológicas/Instituto Federal Farroupilha - Campus Panambi.

2 Acadêmico em Licenciatura em Ciências Biológicas/Instituto Federal Farroupilha - Campus Panambi. Email: renanbornholdt@gmail.com
} 


\section{INTRODUÇÃO}

É inegável o direito dos sujeitos a educação de qualidade, saúde, conhecimento, lazer e acesso ao trabalho.Tais direitos dão aos indivíduos recursos psicológicos e intelectuais para o pleno desenvolvimento de suas capacidades e convívio social como um ser humano.

$\mathrm{Na}$ inclusão, todos os sujeitos necessitam de uma aprendizagem conjunta, onde não há importância sobre as dificuldades e diferenças. (BORGES e JUNIOR, 2018). Começando pelas escolas onde deve haver inclusão e que ela atenda todas as necessidades dos estudantes, levando em conta os ritmos de aprendizagem e priorizando a qualidade de ensino.

No ensino de Ciências para surdos não é diferente. Tais sujeitos que durante várias décadas foram excluídos tanto socialmente quanto academicamente pela sociedade, movimentos sociais e estudos mudaram a realidade da comunidade surda. No caso de sujeitos surdos no ensino regular, há uma tentativa de promover a inclusão. Porém nem tudo acontece da maneira correta, e é comum que sejam deixados de lado, fazendo trabalhos e atividades sozinhos e, por vezes, têm sua capacidade de aprendizagem subestimada, ficando restrito ao contato com o intérprete, criando diante disso uma certa dependência do mesmo (BORGES e JUNIOR, 2018).

Para que esse ensino de aprendizagem seja de qualidade e tenha a inclusão de todos é necessário buscar práticas pedagógicas para solucionar esses problemas e explorar o cognitivo dos alunos, respeitando suas individualidades (aprendizagens próprias). Para que esse processo aconteça, as metodologias devem abranger diversas linguagens (principalmente visuais) para os sujeitos surdos, pois normalmente o estudo é por meios de linguagens orais e escritas para os demais alunos e também a limitação tanto de professores quanto alunos sobre a língua de sinais. Logo essa falta de inclusão pode acabar desmotivando o aluno surdo e consequentemente causando a evasão escolar. (BORGES e JUNIOR, 2018).

Partindo deste contexto, questionamos: Como se dá o processo de ensino de ciências para surdos? $\mathrm{Na}$ intenção de pensar e problematizar tal questionamento, este artigo tem como objetivo revisar e analisar práticas e metodologias que auxiliam no processo pedagógico de ensino/aprendizagem de surdos. Além disso, entender quem é o 
sujeito surdo; os processos legais e seus direitos diante a educação; e os processos de aprendizagem do sujeito surdo.

Primeiramente abordamos sobre o sujeito surdo ao longo da história, onde situamos sobre toda a relação dos sujeitos surdos com a comunidade, incluindo as escolas. Após essa breve explicação discorremos sobre os marcos legais da educação de surdos, onde indicamos as leis e políticas sobre o mesmo. E, por fim, tratamos de metodologias na prática do ensino para sujeitos surdos.

\section{METODOLOGIA}

Há diversos caminhos para se seguir diante da reflexão sobre a produção de um material no aspecto do conhecimento na área científica. Neste caso, a opção foi por meio de uma revisão bibliográfica, realizada a partir da abordagem de pesquisa de artigos científicos e teses no âmbito do ensino e metodologias para sujeitos surdos.

$\mathrm{Na}$ análise dos artigos seguidos buscamos encontrar as ideias de: quem é o sujeito surdo, seus desafios ao longo da história, sua situação atual nos modelos e metodologias usadas em sala de aula.

Em síntese, foram percorridos os seguintes passos de análise: (a) leitura de cada artigo visando o entendimento global a ideia da descoberta abordada pelos autores; (b) classificar as ideias em torno do núcleo do tema, ensino de ciências para surdos; (c) comparar os diferentes núcleos em torno do sentido dos artigos selecionados (d) redação das sínteses interpretativas de cada tema visando atingir o objetivo central; construir conhecimento para um melhor entendimento de como proceder em âmbito de sala de aula.

\section{O SUJEITO SURDO AO LONGO DA HISTÓRIA E AS METODOLOGIAS DA ÉPOCA}

Durante várias décadas os surdos foram considerados seres retardados e incapazes de pensar. "Acreditava-se que o pensamento não podia se desenvolver sem a linguagem e que a fala não se desenvolvia sem a audição: quem não ouvia, portanto, não falava e não pensava” (STREIECHEN, 2012, p. 13). Tal prática e pensamento levantou uma grande barreira na educação de surdos. 
Os pensamentos da época giravam em torno da impossibilidade dos surdos de desenvolver faculdades intelectuais e com tal atitude eram impedidos de frequentar a escola, preconceito esse que não se limitava à área acadêmica. De fato, a reclusão era tanta que eles recaíram aos olhares da igreja, que os viam como pecadores incapazes de confessar seus pecados, logo eram também impedidos de realizar os ritos de iniciação, atividades que na época eram importantes socialmente, reforçando ainda mais a não socialização e a exclusão do sujeito surdo com as outras pessoas, tornando a realidade do surdo um descaso à marginalidade.

Passado algumas décadas, juntamente com estudos, pesquisas, lutas e movimentos sociais, essa realidade começou a mudar lentamente. De acordo com Goldfeld (2002) os primeiros educadores de surdos surgiram na Europa, no século XVI, criando diferentes metodologias para o ensino, entre elas se destacavam a linguagem oral auditiva, a língua dos sinais, a datilografia e outros códigos visuais.

No âmbito nacional esse processo de ensino começa a partir do ano de 1855 , com a contratação de Hernest Huet, e em I857, no Rio de Janeiro, é criada a primeira escola para surdos, atualmente chamada de Instituto Nacional de Educação de Surdos (INES) (GOLDFELD, 2002). Durante os anos houve mudanças na direção da escola e ocorreu uma divergência de interesses, a autora MOURA (1996) explica que:

Em I868, uma inspeção do governo no instituto verificou que ele estava
servindo apenas de asilo de surdos. O diretor foi demitido e, em seu lugar,
foi nomeado o Dr. Tobias Leite. Em I873, foi aprovado o projeto de
regulamento em que era estabelecida a obrigatoriedade de ensino
profissional e o ensino da "linguagem articulada e leitura sobre os lábios."
(MOURA, 1996, p.82)

Nota-se então a preocupação com a educação surda e a necessidade de profissionais capacitados e que entendessem as metodologias de ensino, para que tal espaço deixasse de ser um armazém de surdos e se tornasse uma estrutura para o aprendizado.

Segundo POKER (2002), apesar da disseminação das línguas de sinais a partir de ı86o ocorreram avanços tecnológicos que "facilitaram" a aprendizagem da fala pelas pessoas surdas, sendo assim o método Oral ganhou força. $O$ autor ainda aponta para Alexander Graham Bell, o mais importante defensor do Oralismo, resultando em grande influência na votação do congresso Internacional de Educadores de Surdos, em I88o. O 
Oralismo venceu e o uso de sinais foi oficialmente proibido, importante ressaltar que nesta ocasião professores surdos foram negados o direito de votar.

O oralismo então passou a dominar as escolas surdas, as matérias disciplinares eram deixadas de lado para o treinamento oral levando a uma queda no nível de escolarização dos alunos surdos. Tal prática de ensino dominou até a década de sessenta quando William Stokoe publicou um artigo demonstrando a importância cultural da linguagem de sinais, assim como a mesma possui as mesmas características das linguagens orais, a partir daí outras publicações vieram reforçando a necessidade dos sinais assim como a insatisfação dos surdos com a oralidade (POKER,2002).

O autor POKER (2002) aponta que a filosofia da comunicação total chega em 1968, utilizando todas as formas de comunicação adequadas e possíveis para o sujeito, acreditando-se que a comunicação e não apenas a língua, deve ser privilegiada. $O$ autor ainda continua dizendo que a partir da década de setenta, a língua de sinais deve ser independente da linguagem oral, trazendo assim a filosofia bilíngue, que vem se disseminando por todo o mundo.

Nas últimas décadas ocorreram diversas mudanças significativas e memoráveis para a comunidade surda, como o Decreto 5.626/2005 que regulamenta a Lei 10.436/2002. No Capítulo I Art. $2^{\circ}$, considera como surdo um indivíduo que, por meio de perda auditiva, compreende o mundo e interage por meio de experiências visuais, tendo manifestação cultural principalmente pelo uso de sinais - LIBRAS.

Em relação a identidade surda a comunidade ouvinte comete alguns equívocos e possuem dúvidas sobre o grupo social em questão. É comum e quase um dilema entre os ouvintes a respeito de qual terminologia utilizar quando se dirige ao sujeito, "deve-se usar o termo portador da surdez, surdo ou deficinete auditivo?”.

Embora ocorreram diversas mudanças, tanto tecnológicas no âmbito do acesso à informação, quanto legais, na estruturação da comunidade humana em si, ainda é notado que boa parte da população vem fazendo uso de terminologias que trazem para a comunidade surda um desconforto e transmitem um estigma negativo e uma visão preconceituosa. 
Para se dirigir a tal sujeito existem terminologias que devem ser adotadas, por questões de respeito e para evitar desentendimentos, o primeiro termo abordado será o surdo-mudo e mudo.

Sem dúvidas esta é uma das nomenclaturas mais antigas quando se referencia ao sujeito surdo e provavelmente a mais antiquada, já que surdo é um sujeito que possui perda auditiva, já mudo é um sujeito que possui incapacidade de vocalizar, sendo que, uma característica não está vinculada a outra, muito pelo contrário, os surdos são sujeitos "falantes" dentro de sua própria língua, sendo assim este termo é um tanto ultrapassado e deve ser deixado de lado, pois dizer que alguém é MUDO pelo simples fato de não vocabular ou possuir dificuldades para tal é um tanto preconceituoso (CARDOSO, 20I6). Portanto, devemos desvincular tais palavras e usarmos o termo "surdo".

O próximo vocabulário é o deficiente auditivo. Segundo Cardoso (2013), deficiente auditivo é aquele que tem perda parcial da audição, ou seja, escuta o mínimo de ruído possível. $\mathrm{O}$ autor ainda explica que existem duas vertentes quando o termo se aplica a um surdo, os que não gostam e os que não se opõem.

Karin L. Strobrel, citada em Barros e Hora (2009, p. 18) diz: “a terminologia 'deficiente auditivo' tem sido rejeitada pelos surdos/as por ser fruto de representações construídas pela medicina, a qual considera que aqueles são doentes e/ou deficientes e, categoriza-os de acordo com o grau da surdez, entre leve, moderado, severo ou profundo”.

O Autor Cardoso (2016) ainda levanta que nesse mesmo estudo de Barros e Hora (2009, p. I8) as autoras dizem: "Porém, ressaltamos que, contraditoriamente, há pessoas surdas que assumem os termos "deficiente auditivo", "D.A." e "pessoa com deficiência auditiva" consciente ou inconscientemente, outras os utilizam apenas em determinados espaços sociais para poder usufruir direitos que lhes são garantidos pela legislação e políticas sociais"

Sem dúvida o termo mais aceito entre pesquisadores da área, o autor Cardoso (2016) ainda ressalta o uso da maiúscula na palavra Surdo, que explica a herança norte-americana, pois no Estados Unidos se grafa com maiúscula a letra inicial de povos e línguas, como por exemplo "Black" (Negro) e "Deaf" (Surdo).

Lane apud Bisol \& Sperb (2oro, p. 8) afirma que: Ser Surdo (com "S" maiúsculo) é reconhecer-se por meio de uma identidade compartilhada por pessoas que utilizam língua 
de sinais e não vêem a si mesmas como sendo marcadas por uma perda, mas como "membros de uma minoria linguística e cultural com normas, atitudes e valores distintos e uma constituição física distinta".

Portanto, se quiser se referir a alguém da comunidade surda, sem causar nenhum desconforto para o mesmo, use a palavra "Surdo". De tal maneira você estará reconhecendo ele dentro de sua comunidade e aceitando a sua identidade e cultura, sem estigmas ou termos herdados de preconceitos.

\section{MARCOS LEGAIS SOBRE A EDUCAÇÃO DE SURDOS}

A Lei no 10.436 de 2002 é considerada um marco na história da educação de surdos, pois sua concretização é resultado das lutas políticas levantadas pelos órgãos representativos da comunidade surda pelo direito linguístico das pessoas surdas no Brasil. Foi promulgada em 24 de abril de 2002, sendo reconhecida a Libras como meio legal de comunicação e expressão. Porém, além de reconhecer a língua, ela também diz no terceiro parágrafo que as "instituições públicas e empresas concessionárias de serviços públicos de assistência à saúde devem garantir atendimento e tratamento adequado aos portadores de deficiência auditiva, de acordo com as normas legais em vigor" (BRASIL, 2002).

Em 2005 o Decreto 5.626/o5 regulamenta a Lei $n^{\circ}$ I0.436, ou seja, possui a intenção de especificar as disposições gerais e abstratas da Lei, viabilizando sua aplicação em casos específicos. O presente Decreto considera “pessoa surda aquela que, por ter perda auditiva, compreende e interage com o mundo por meio de experiências visuais, manifestando sua cultura principalmente pelo uso da Língua Brasileira de Sinais - Libras" (BRASIL, 2005).

Nas Diretrizes da Política Nacional de Educação Especial na Perspectiva da Educação Inclusiva (2008) diz que, do nascimento à idade adulta, toda e qualquer pessoa necessitada tem direito à educação inclusiva, e conta com os respectivos serviços de saúde e assistência social, devendo implantar regime especial na própria escola ou em instituições especializadas no período oposto ao da educação formal.

No campo da educação especial, é necessária uma formação especial, pois além de considerar os saberes de gestão do sistema de educação inclusiva, também é possível formular estratégias relacionadas à prática cotidiana a fim de desenvolver projetos em 
cooperação com outras áreas, permitindo, assim, a qualidade de vida em diferentes departamentos, por exemplo, saúde, assistência social, etc.

De tal modo, o sistema educacional deve participar da formação de diferentes campos relacionados à aprendizagem, de forma a valorizar as diferenças e auxiliar os alunos da melhor forma no que se refere às necessidades educacionais.

Para que os alunos surdos tenham um ensino de aprendizagem adequado e de qualidade é necessário um intérprete para lhe auxiliar, por isso a tradução e interpretação profissional de Libras foi aprovada pela Lei no 12.319 em I을 de setembro de 2010. Levando em consideração as exigências dos intérpretes, tal projeto de lei gerou novas discussões sobre os parâmetros para o desempenho da função, como treinamento, atuação, sindicalização e valorização do evento (BRASIL, 2010).

E por fim a Lei Brasileira de Inclusão (LBI), é um conjunto de normas que visa garantir a promoção e o exercício igualitário dos direitos e liberdades fundamentais das pessoas com deficiência para sua inclusão social. A Lei foi promulgada em 6 de julho de 2015, mas após cumprir um período de vacância (período entre a data da publicação de uma lei e o início de sua vigência) de I8o dias, entrou em vigor em 3 de janeiro de 2016.

A principal inovação da LBI consiste na alteração do conceito jurídico de “deficiência”. Esta alteração já não é considerada como uma condição estática e biológica da pessoa, mas como o resultado da interação de obstáculos criados pelo ambiente e limitações físicas, intelectual, mental e sensorial. Conforme o artigo $2^{\circ}$ : “considera-se pessoa com deficiência aquela que tem impedimento de longo prazo de natureza física, mental, intelectual ou sensorial, o qual, em interação com uma ou mais barreiras, pode obstruir sua participação plena e efetiva na sociedade em igualdade de condições com as demais pessoas" (BRASIL, 2015).

Porém, e mesmo com as várias legislações aprovadas, ainda há certa resistência quanto à inclusão dos sujeitos surdos. Alguns profissionais da área de ensino ainda se encontram despreparados para mediar o ensino $e$ não conhecem as estratégias $e$ metodologias necessárias para trabalhar com surdos, ocasionando lacunas no conhecimento do mesmo, resultando em reprovações, em casos mais graves, aprovações do sujeito sem nem saber ler ou escrever. 


\section{ENSINO DE CIÊNCIAS PARA SURDOS}

A escola deve ser um local confortável e aconchegante para os alunos. A inclusão, como um processo de igualdade, é um direito de todo sujeito e tal processo certamente é um desafio, ainda mais quando se trata de uma pessoa surda, pois essa historicamente tem sido negligenciada durante séculos.

A presença de um aluno surdo em uma sala de aula exige que o docente reconheça a necessidade da elaboração de estratégias e métodos que sejam adequados para as necessidades do sujeito. Um professor de Ciências, como mediador do ensino, deve ter como objetivo prover um ambiente agradável e suprir as necessidades do aluno a fim de promover avanços e dar continuidade das transformações pessoais e desenvolvimento do indivíduo.

A Ciência é uma matéria ligada diretamente à humanidade e sua história, desde o princípio da vida até os confins do universo, ou na resolução dos simples problemas do dia a dia, estudar e aprender ciências é identificar pensamentos e teorias que tentam encontrar significado na natureza, trabalhando assim e trazendo consigo os aspectos físicos, químicos e biológicos de todas as formas de vida e matéria.

De fato, o campo da ciência é amplo, mas se fôssemos resumir em apenas uma frase seria "encontrar um sentido nas coisas, conhecer a si mesmo e os acontecimentos ao seu redor”. Na verdade, o estudo da ciência é mais uma maneira de se encontrar e se identificar diante da natureza e tal reconhecimento e apropriação de certa identidade nos leva a fazer uma ligação direta da necessidade da LIBRAS, pois tal língua consegue expressar o mundo de uma maneira conecta com o mundo em que o surdo vive, usar a mesma língua para compreender o sentido das palavras e dos objetos.

Mas talvez você se encontre confuso sobre alguns temas, como explicar termos complexos e conceitos complicados como barreira do som para uma pessoa surda, já que a mesma não consegue ouvir o próprio som em questão?,Logo, como ela poderá compreender a quebra dessa barreira? Como explicar para um aluno sobre os comprimentos de onda e como eles se comportam na natureza? Bem, a resposta é mais simples do que aparenta:Use uma metodologia que se encaixe/adeque a realidade do aluno.

$\mathrm{Na}$ verdade essas limitações são mais psicológicas na mente dos docentes do que reais. Para explicar ambos os casos anteriores, nós, professores de ciências, utilizamos de 
gráficos, desenhos, quadrinhos, entre outros materiais visuais. Você consegue apenas com a teoria do som, das ondas, fazer com que um aluno surdo consiga compreender e contextualizar o que é um som, ou pelo menos uma onda, já que se observarmos outras propriedades físicas podemos ver as mesmas ondas na natureza, como na luz por exemplo, as cores, também possuem comprimento de ondas, e por meio desse caminho, podemos conseguir trazer a clareza de como um som pode se comportar.

O som também, sendo uma onda, reflete e é repelido em certas superfícies, gerando vibrações, tais vibrações são sensíveis à pele, aos músculos. Para isso, use um aparelho de som com volume alto na sala de aula e será suficiente para contextualizar no dia a dia o som para uma pessoa que talvez nunca tenha ouvido um. De fato, há vários artistas surdos que são ótimos músicos.

Foi usado o tema "som" como foco nesse exemplo com o princípio de causar inquietação no leitor, pois ressaltamos, se conseguimos através de estratégias e metodologias diferentes contextualizar para um sujeito surdo algo que ele até então pode não ter experimentado. Qual é a justificativa para criar barreiras no ensino?

Há diversos caminhos para se seguir diante da reflexão e da necessidade sobre a produção de um material adaptado seguindo as metodologias estratégicas adequadas à forma de aprendizagem deste aluno. No campo educacional existem várias metodologias e abordagens para o ensino de surdos e a maioria consiste em substituir a audição por outro canal sensorial, como a visão, o tato, aproveitando-se das habilidades dos indivíduos.

Os métodos de ensino dividem-se em três abordagens principais que acabam por produzir diversas formas de como se trabalhar com o aluno surdo. São elas: Oralismo, Comunicação Total e Bilinguismo.

\section{ORALISMO}

O Autor Goldfield (1997) diz que a filosofia oralista visa a integração da criança surda na comunidade ouvinte e que para alguns defensores dessa filosofia, a linguagem restringe-se apenas a língua oral, defendendo a ideia de que para uma criança surda se comunicar é necessário que ela saiba falar. $O$ autor defende a ideia de que a surdez é uma deficiência que deve ser amenizada com estímulos auditivos, possibilitando assim a 
criança de falar, integrando-a a sociedade, em suas palavras, reabilitando a criança a normalidade.

Tal método exige muito do sujeito, já que a oralidade não condiz com sua realidade nem com suas experiências vividas, é uma busca por algo que não se encontra. Para os defensores desse método é necessário, dedicação das pessoas ao redor da criança para a reabilitação em direção à "normalidade", início do tratamento o mais cedo possível, não dispor de nenhuma outra modalidade de linguagem fora a oral, requer a participação de um profissional especializado, como fonoaudiólogo e um pedagogo para ajudar sistematicamente o aluno e a família, assim como equipamentos especializados como o aparelho de amplificação sonora individual. O Autor (POKER,2002) dá alguns exemplos de metodologias de oralização: método acupédico, método Perdoncini, método verbo-tonal, entre outros.

Em resumo, o Oralismo transforma as escolas em salas de tratamento, devido à sua influência da medicina, trata a surdez como uma deficiência que deve ser amenizada com tecnologia, trazendo ao sujeito surdo a normalidade da fala orada.

\section{COMUNICAÇÃO TOTAL}

O autor POKER (2002) define a comunicação total como a filosofia da incorporação de modelos não só auditivos, mas também manuais e orais para assegurar um mais amplo campo de comunicação a fim de assegurar os processos comunicativos entre surdos e surdos, e entre surdos e ouvintes.

Tal prática não deixa de lado o ensino do oralismo, mas após a constatação que os surdos nunca conseguiriam se comunicar de maneira clara e satisfatória com o método Oralista e insistiam em usar a língua de sinais para a comunicação, foi decidido então um método mais livre, com uso de outras ferramentas e principalmente auxílio visual. Este modelo combinava a língua de sinais, gestos, mímicas, leitura labial, entre outros recursos que colaboraram com o desenvolvimento da língua oral (SCHELP, 2008).

O autor (POKER,2002) contextualiza que a Comunicação Total valoriza a comunicação e a interação e não apenas a língua. Seu objetivo maior não se restringe ao aprendizado de uma língua e sim a busca pela compreensão das informações, sentimentos e expressões da pessoa surda. $O$ autor ressalta algumas metodologias utilizadas nesse 
processo como: ao alfabeto digital; a língua de sinais;a amplificação sonora; ao português sinalizado.

\section{BILINGUISMO}

Esse método parte de um princípio mais cultural, de reconhecimento como uma comunidade própria. $\mathrm{O}$ bilinguismo foi uma metodologia reivindicada a partir dos próprios surdos (KALATAI, 2012) e nesse método aprende-se primeiro a língua de sinais, como sua língua primária. Os defensores desse método defendem que cada língua possui suas próprias características e heranças culturais, logo a língua de sinais consegue contextualizar melhor a realidade vivida e experienciada pelo sujeito surdo. A língua portuguesa é ensinada como uma língua secundária, na modalidade escrita e, quando cabível na oralidade.

O autor Brito (1993) defende que a língua de sinais é uma importante via para o desenvolvimento do sujeito surdo em todas as suas esferas de conhecimento, como tal "propicia não apenas a comunicação surdo - surdo, além de desempenhar a importante função de suporte do pensamento e de estimulador do desenvolvimento cognitivo e social".

Como já dito, os bilíngues defendem a ideia da formação de uma comunidade, com sua própria cultura e língua, sendo assim uma diferente forma de se manifestar, pensar e agir, que deve ser respeitada.

A autora KALATAI(2012) salienta que "a preocupação do bilingüismo é respeitar a autonomia das línguas de sinais organizando-se um plano educacional que respeite a experiência psicossocial e linguística da criança com surdez”. Ela continua dizendo que a língua de sinais no Brasil é denominada de Língua Brasileira de Sinais (Libras) e vem se destacando em virtude dos movimentos da Comunidade e pelo processo de inclusão de alunos surdos na rede de ensino regular.

As faculdades têm buscado oferecer a disciplina de LIBRAS em todos os cursos de licenciatura por meio do Decreto 5626/2005, da Lei 10.436/2002, Artigo 3ํ (BRASIL, 2005) que se tornou obrigatório. Desta forma, a LIBRAS deixa de ser uma língua restrita aos surdos e passa a se tornar conhecida por demais pessoas. A autora KALATAI(2012) ainda 
defende que "este sempre foi o objetivo da Comunidade surda brasileira: a difusão da Língua de Sinais".

\section{CONSIDERAÇÕES FINAIS}

O presente artigo teve como objetivo realizar uma pesquisa bibliográfica, começando sobre o sujeito surdo ao longo da história, no qual percebemos que foi através de estudos, pesquisas, lutas e movimentos sociais que a realidade dos surdos, que era a exclusão do mesmo, começou a mudar. Porém, em âmbito nacional, foi a partir de 1855 , onde a primeira escola para surdos foi criada. Notou-se então que a preocupação com o ensino dos surdos foi se complementando e modificando até os dias atuais. Um tópico bem analisado e discutido foi sobre as terminologias que devem/podem ser adotadas por questões de respeito para evitar desentendimentos. Foi de surdo-mudo para Surdo (com letra maiúscula).

Em sequência foi possível analisar e compreender os marcos legais sobre a educação de surdos de 2002 à 2015, começando por um dos maiores marcos da comunidade de surdos que é a Lei $\mathrm{n}^{\circ}$ I0.436/o2, pois sua concretização foi resultado de uma luta levantada pelos órgãos representativos da comunidade surda. Nela foi reconhecida a Libras como um meio legal de comunicação e expressão. Nesse tópico foi possível verificar como as leis, decretos e diretrizes ajudaram e ajudam para que a comunidade surda seja reconhecida e incluída principalmente na educação.

E, por fim, a última temática foi o nosso principal assunto, pois fala sobre o ensino de ciências para surdos onde discorremos sobre como o docente deve reconhecer a necessidade de elaboração de estratégias e métodos que sejam adequados para os sujeitos. Também afirmamos como o ensino de ciências é importante para a compreensão de aspectos físicos, químicos e biológicos.

$\mathrm{Na}$ sequência, mencionamos as três abordagens principais para se trabalhar com o aluno surdo. A primeira é o oralismo que transforma as escolas em salas de tratamento, trata a surdez como uma deficiência que deve ser amenizada com tecnologia, trazendo ao sujeito surdo a normalidade da fala orada. A segunda abordagem é a comunicação total, onde a incorporação não só de modelos auditivos, mas também manuais e orais para a comunicação entre surdos e surdos e surdos e ouvintes. E, por último, o bilinguismo, 
onde se aprende primeiro a língua dos sinais e a língua portuguesa por segundo, onde priorizam suas próprias linguagens e culturas (método mais aceito pela comunidade surda atualmente).

Portanto, podemos compreender a história da educação de surdos e o uso de ao longo dos anos diferentes métodos de ensino. Desta forma, aprendemos também sobre as particularidades dos surdos, a sua língua e a vida social relacionada com o processo de inclusão.

\section{REFERÊNCIAS}

BARROS, Josibel Pereira; HORA, Mariana Marques. Pessoas Surdas: Direitos, Políticas Sociais e Serviço Social. Monografia de Serviço Social UFPE. RecifePE, 2009. Disponível em: araraazul.com.br/cadernoacademico/or2_anexos_pessoas_surdas_direitos_politicas_sociais_ e_servico_social_barros_hora.pdf Acesso em is fev. 2021

BRASIL. Lei no 13.146, de o6 de julho de 2015. Institui o Código Civil. Brasília, DF: Presidência da República, 2015. Disponível em: http://www.planalto.gov.br/ccivil_03/_ato2015-2018/2015/lei/li3146.htm Acesso em: I2 mar. 202I.

BRASIL. Lei no 10.436 , de 24 de abril de 2002. Institui o Código Civil. Brasília, DF: Presidência da República, 2002. Disponível em: http://www.planalto.gov.br/ccivil_03/leis/2002/1ro436.htm Acesso em: I2 mar. 2021.

BRASIL. Decreto no 5.626, de 22 de dezembro de 2005. Institui o Código Civil. Brasília, DF: Presidência da República, 2002. Disponível em: http://www.planalto.gov.br/ccivil_03/_at02004-2006/2005/decreto/d5626.htm Acesso em: I2 mar. 2021.

BRASIL. Lei no ${ }^{\mathbf{1 2} .319}$, de $\mathbf{I}^{\circ}$ de setembro de 2010. Institui o Código Civil. Brasília, DF: Presidência da República, 2002. Disponível em: http://www.planalto.gov.br/ccivil_03/_at02007-2010/2010/lei/112319.htmr . Acesso em: I2 mar. 2021.

BRITO, L.F. Integração social e educação de surdos. Rio de Janeiro : BABEL Editora, I993

BISOL, C.; SPERT,T. M. Discursos sobre a Surdez: Deficiência, Diferença,Singularidade e Construção de Sentido. Psic.: Teor. e Pesq., Brasília, Jan-Mar 2oro, Vol. 26 n. I, pp. 7-13

BORGES, R.B.; JUNIOR, M. J. T. O intérprete de Libras no ensino de Ciências e Biologia para alunos surdos. Revista de Ensino de Biologia da SBEnBio/ISSN: 1982- I867, Uberlândia, v.I, n.2, p.6I-76, 2018. 
GOLDFELD, Marcia. A criança surda - linguagem e cognição numa perspectiva sociointeracionista. $2^{-}$ed. São Paulo: Plexus, 1997.

A criança surda: linguagem e cognição numa perspectiva sóciointeracionista. 2 ed. São Paulo: Plexus, 2002.

KALATAI, Patrícia; STREIECHEN, Eliziane M. As principais metodologias utilizadas na educação dos surdos no Brasil. In: III SEPED - Semana de Estudos do Curso de Pedagogia de Irati, 2012. Irati. Anais...Disponível em: http://anais.unicentro.br/seped/pdf/iiiv3nI/r2o.pdf. Acesso em: I6 fev. 202I

MOURA, Maria Cecília de. O surdo: caminhos para uma nova identidade. Tese de Doutorado Psicologia Social, São Paulo, 1996.

POKER, R. B. Troca simbólica e desenvolvimento cognitivo em crianças surdas: uma proposta de intervenção educacional. Tese de doutorado. UNESP - Marília, 2002.

STREIECHEN, Eliziane Manosso. Língua Brasileira de Sinais: LIBRAS; ilustrado por Sérgio Streiechen. Guarapuava: UNICENTRO, 2012.

SCHELP, Patrícia Paula. Práticas de letramento de alunos surdos em contexto de escola inclusiva. Universidade Regional do Noroeste do Estado do Rio Grande do Sul. Ijuí, 2008. 